\title{
Quality assessment and improvement of the EUMETSAT Meteosat Surface Albedo Climate Data Record
}

\author{
A. Lattanzio $^{1}$, F. Fell ${ }^{2}$, R. Bennartz ${ }^{3}$, I. F. Trigo ${ }^{4}$, and J. Schulz ${ }^{1}$ \\ ${ }^{1}$ EUMETSAT, Darmstadt, Germany \\ ${ }^{2}$ Informus GmbH, Berlin, Germany \\ ${ }^{3}$ University of Wisconsin-Madison, Space Science and Engineering Center, Madison, USA \\ ${ }^{4}$ Instituto Portugues do Mar e da Atmosfera (IPMA), Lisbon, Portugal \\ Correspondence to: A. Lattanzio (alessio.lattanzio@eumetsat.int)
}

Received: 28 April 2015 - Published in Atmos. Meas. Tech. Discuss.: 23 July 2015

Revised: 19 October 2015 - Accepted: 21 October 2015 - Published: 30 October 2015

\begin{abstract}
Surface albedo has been identified as an important parameter for understanding and quantifying the Earth's radiation budget. EUMETSAT generated the Meteosat Surface Albedo (MSA) Climate Data Record (CDR) currently comprising up to 24 years (1982-2006) of continuous surface albedo coverage for large areas of the Earth. This CDR has been created within the Sustained, Coordinated Processing of Environmental Satellite Data for Climate Monitoring (SCOPE-CM) framework. The long-term consistency of the MSA CDR is high and meets the Global Climate Observing System (GCOS) stability requirements for desert reference sites. The limitation in quality due to non-removed clouds by the embedded cloud screening procedure is the most relevant weakness in the retrieval process. A twofold strategy is applied to efficiently improve the cloud detection and removal. The first step consists of the application of a robust and reliable cloud mask, taking advantage of the information contained in the measurements of the infrared and visible bands. Due to the limited information available from old radiometers, some clouds can still remain undetected. A second step relies on a post-processing analysis of the albedo seasonal variation together with the usage of a background albedo map in order to detect and screen out such outliers. The usage of a reliable cloud mask has a double effect. It enhances the number of high-quality retrievals for tropical forest areas sensed under low view angles and removes the most frequently unrealistic retrievals on similar surfaces sensed under high view angles. As expected, the usage of a cloud mask has a negligible impact on desert areas where clear conditions dominate. The exploitation of the albedo seasonal variation
\end{abstract}

for cloud removal has good potentialities but it needs to be carefully addressed. Nevertheless it is shown that the inclusion of cloud masking and removal strategy is a key point for the generation of the next MSA CDR release.

\section{Introduction}

Surface albedo has been identified as an important parameter for climate change by the Working Group I within the Intergovernmental Panel on Climate Change (IPCC) (Foster et al., 2007). Monitoring this parameter is paramount to understanding the climate system (e.g. Henderson-Sellers and Wilson, 1983) because it is a key forcing variable (e.g. Hansen et al., 1997) and it controls the surface radiation budget (e.g. Pielke and Avissar, 1990). The Global Climate Observing System (GCOS) formulated scientific requirements for climate observations including a list of relevant parameters, the Essential Climate Variables (ECVs), with associated observation requirements (GCOS-138, 2010). One of the terrestrial ECVs is the land surface albedo. This parameter is defined as the ratio of the radiation flux reflected to the incident radiation flux impinging on the surface (SchaepmanStrub et al., 2006). It depends on both the anisotropy of the surface and the atmosphere (e.g. Schaaf et al., 2009). GCOS has specified two variables corresponding to two opposite extreme conditions as satellite-derived products for climate change studies: the black sky albedo (BSA), defined in the absence of a diffuse irradiance component, and the white sky albedo (WSA), defined under pure diffuse irradiance condi- 
tions. Throughout this paper we use the variable directional hemispherical reflectance (DHR) to refer to black sky albedo and the variable bi-hemispherical albedo under isotropic illumination $\left(\mathrm{BHR}_{\mathrm{iso}}\right)$ to refer to white sky albedo. These two parameters can be used to estimate the actual albedo, the blue sky or BHR under ambient conditions (Pinty et al., 2005). EUMETSAT has undertaken an activity to generate a surface albedo data set (Meteosat Surface Albedo, MSA) climate data record (CDR), spanning over more than 2 decades from measurements acquired by the Meteosat Visible and Infrared Imager (MVIRI) instrument onboard the Meteosat First Generation (MFG) satellites (EUMETSAT, 2011). EUMETSAT coordinated a study (ALBEDOVAL) for the validation of the MSA CDR. In the validation report (Fell et al., 2012), the full set of results, including comparison with in situ measurements and satellite retrievals, can be found. This paper focuses on the most relevant positive outcome, i.e. the high temporal stability, and presents a strategy to address the most relevant weakness, i.e. the deficiency in quality due to undetected clouds.

\section{Surface albedo retrieval from geostationary satellites}

Satellite measurements offer an unique opportunity for documenting and monitoring the spatial surface albedo distribution and in particular its variability at continental scales. Observations acquired by instruments onboard geostationary satellites have three major advantages: (i) long-term archived data, (ii) capability of surface sampling under different illumination conditions and (iii) capability of a diurnal sampling of parameters influencing the retrieval such as cloud cover and aerosol load. One drawback is that the retrieval area is limited to a circle with a radius of ca. $65^{\circ}$ around the subsatellite point (SSP).

Another characteristic to consider is that the pixel size is not constant but it depends on the angular distance from the satellite SSP. Most of the albedo retrieval strategies rely on the collection of cloud-free observations to define the bidirectional reflectance distribution function (BRDF). This function is used to characterize the surface angular reflectance properties. The MSA algorithm is based on a method proposed by Pinty et al. (2000a). It performs the inversion of a fast radiative transfer model (RTM), ingesting reanalysis total column water vapour and total column ozone data. The method relies on daily accumulation of clear sky radiances acquired in a single visible band (VIS) and on the applicability of the reciprocity principle (Lattanzio et al., 2006). According to this principle, the bidirectional reflectance distribution function (BRDF) does not change when incident and reflected angles are reversed. Measurements acquired under different illumination conditions can then be interpreted as observations taken under different viewing conditions. One key point is that the method applied in the MSA algorithm allows for a joint retrieval of aerosol load and both black and white sky albedo. An assessment of the measurement error and an estimation of the retrieval uncertainty are performed during the processing for each pixel (Govaerts and Lattanzio, 2007). The algorithm is applied to the native instrument visible band, resulting in spectral albedo values. In the current release of the MSA CDR the products are generated as 10-day composites, except for the last period of each year, which corresponds to 5 or 6 (leap-year) days. The maximum number of available products per year is 37 . The MSA retrieval method is general and it has been applied to the Geostationary Operational Environmental Satellite (GOES) and Geostationary Meteorological Satellite (GMS) observations (Govaerts et al., 2008). This activity has been performed within the World Meteorological Organization (WMO) Sustained, Coordinated Processing of Environmental Satellite Data for Climate Monitoring (SCOPE-CM) framework (Lattanzio et al., 2013).

\section{Requirements and validation}

During the past 10 years, much effort has been made to establish proper CDR requirements for detecting and assessing climate change. The analysis focused mainly on accuracy and stability (Ohring et al., 2005) and recently also on the necessary length of a data set for detecting a real change (Loew, 2014). The requirements defined by GCOS for land surface albedo are reported in Table 1 . The rationale behind these requirements is to allow the detection of changes in the radiative forcing equivalent to $20 \%$ of the expected variation per decade due to greenhouse gases and other forcing, i.e. $0.1 \mathrm{~W} \mathrm{~m}^{-2}$ per decade (GCOS-154, 2011). A key aspect in the generation of a CDR is the assessment of the uncertainty associated with the geophysical variable retrieved. Such a parameter is essential to determine whether a detected change or trend is statistically significant or within the measurement uncertainty.

EUMETSAT coordinated a study (ALBEDOVAL) for the validation of the MSA CDR performed by a group of independent researchers in Europe and US. The validation focused on four main aspects: (1) uncertainty assessment, (2) temporal consistency, (3) validation against in situ measurements and (4) comparison with other satellite estimates.

In order to quantify the stability and to assess the quality of the MSA CDR, various data sources have been exploited. These include satellite data and in situ measurements. The subset of validation data suitable for the objective of this paper is listed in Sect. 3.2. A systematic comparison of the MSA with in situ observations is problematic due to the lack of direct albedo measurements representative of the large areas covered by individual MSA pixels. Most of the FLUXNET (Cescatti et al., 2012) or the Baseline Surface Radiation Network (BSRN) sites (Ohmura et al., 1998) providing surface albedo observations are located in rather heterogeneous landscapes and are thus not well suited for 


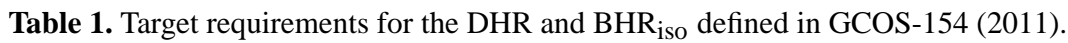

\begin{tabular}{lccc}
\hline Variable/parameter & Temporal resolution & Accuracy & Stability \\
\hline Black sky albedo & Daily to weekly & $\operatorname{Max}(5 \% ; 0.0025)$ & $\operatorname{Max}(1 \% ; 0.0001)$ \\
White sky albedo & Daily to weekly & $\operatorname{Max}(5 \% ; 0.0025)$ & $\operatorname{Max}(1 \% ; 0.0001)$ \\
\hline
\end{tabular}

MSA validation. In the context of the ALBEDOVAL study, a very limited number of ground sites have been identified as potential candidates for a direct case-based comparison with MSA retrievals. Satellite data used for comparison include products generated with the Moderate Resolution Imaging Spectroradiometer (MODIS) (Schaaf et al., 2002) and with the Multi-angle Imaging SpectroRadiometer (MISR) (Martonchik et al., 1998) instruments. The full set of comparison results can be found in the validation report (Fell et al., 2012).

\subsection{MSA data}

The MSA CDR has been derived from imagery acquired by the MVIRI radiometer onboard MFG satellites. The MVIRI field of view is centred in the SSP with a radius of ca. $65^{\circ}$. The main mission of these satellites was to provide data for the $0^{\circ}(0 \mathrm{DEG})$ service area covering most of Europe, Africa, the Middle East and the eastern parts of South America. In order to bridge a gap in the availability of GOES, between 1991 and 1995 , Meteosat-3 was moved first to $50^{\circ} \mathrm{W}$ and, in early 1993 , to $75^{\circ} \mathrm{W}$. These temporary services, called Atlantic Data Coverage (ADC) and Extended-ADC (XADC), respectively, had the primary purpose of supporting the monitoring of severe weather events such as hurricanes. Following the requirements of the Indian Ocean Experiment (INDOEX) (Ramanathan et al., 1995), the Indian Ocean Data Coverage (IODC) mission was established and Meteosat-5 was moved to $63^{\circ} \mathrm{E}$ in 1997 . MVIRI data acquired at this position are available from mid-1998 to 2007. As a continuation of the IODC mission, Meteosat-7 has been positioned at $57.5^{\circ} \mathrm{E}$ from where it has acquired data since November 2006. Detailed information about the MSA data set availability is given in Table 2 . The data set can be requested from the EUMETSAT Data Centre (https://eoportal.eumetsat.int) free of charge after registration. Users can request the product in the Binary Universal Form for the Representation of Meteorological data (BUFR) and in Hierarchical Data Format 4 (HDF4) formats. User documentation, consisting of an Algorithm Theoretical Base Document (ATBD), Product User Guide (PUG) and Validation Report (VR), is available for download from the EUMETSAT web page.

\subsection{Validation data}

In situ measurements and a different satellite-derived albedo product have been used for assessing the impact of nonremoved clouds. Ground measurements from the Southern African Regional Science Experiment (SAFARI) campaign
Table 2. Overview of MVIRI observations history in standard operation mode. The coverage acronyms refer to Indian Ocean Data Coverage (IODC) and (Extended) Atlantic Data Coverage ((X)ADC). The corresponding subsatellite points (SSP) are also indicated.

\begin{tabular}{lccll}
\hline Coverage & SSP & Satellite & Start date & End date \\
\hline & $0^{\circ}$ & M2 & 16 Aug 1981 & 11 Aug 1988 \\
& $0^{\circ}$ & M3 & 11 Aug 1988 & 25 Jan 1991 \\
0DEG & $0^{\circ}$ & M4 & 19 Jun 1989 & 4 Feb 1994 \\
& $0^{\circ}$ & M5 & 2 May 1991 & 13 Feb 1997 \\
& $0^{\circ}$ & M6 & 21 Oct 1996 & 20 Jan 2000 \\
& $0^{\circ}$ & M7 & 3 Jun 1998 & 19 Jul 2006 \\
\hline IODC_63 & $63^{\circ} \mathrm{E}$ & M5 & 1 Jul 1998 & 16 Apr 2007 \\
IODC_57 & $57^{\circ} \mathrm{E}$ & M7 & 1 Nov 2006 & Ongoing \\
\hline ADC & $50^{\circ} \mathrm{W}$ & M3 & 1 Aug 1991 & 27 Jan 1993 \\
\hline XADC & $75^{\circ} \mathrm{W}$ & M3 & 21 Feb 1993 & 31 May 1995 \\
\hline
\end{tabular}

(Privette et al., 2005) have been compared with MSA retrievals over a tropical forest site in Africa. A comparison over a larger area has been performed using the surface albedo data set (Geiger et al., 2008) generated using imagery acquired from the Spinning Enhanced Visible and Infrared Imager (SEVIRI) radiometer onboard Meteosat Second Generation (MSG) satellites at the EUMETSAT Land Surface Analysis Satellite Application Facility (LSA SAF) (Trigo et al., 2011). The SEVIRI cloud mask takes advantage of the instrument's better spectral resolution, and its $15 \mathrm{~min}$ temporal frequency increases the chances of gathering clear sky observations. DHR values are estimated at local noon for the MSG SAF data set and at a default solar zenith angle of $30^{\circ}$ in the case of the MSA CDR. As a reference for assessing the impact of the uncertainty in the retrieval due to aerosol estimation, 18 stations (in Europe, Africa and the Arabic peninsula) of the AErosol RObotic NETwork (AERONET) (Holben et al., 1998) have been used. The AERONET aerosol optical depth (AOD), which is specified for $675 \mathrm{~nm}$, was referenced to $550 \mathrm{~nm}$ (reference wavelength of the MSA AOD) by using the Angstrom coefficient derived from concurrent observations at $870 \mathrm{~nm}$. The AERONET values reformatted in this way were then averaged to match the 10-day MSA periods. 

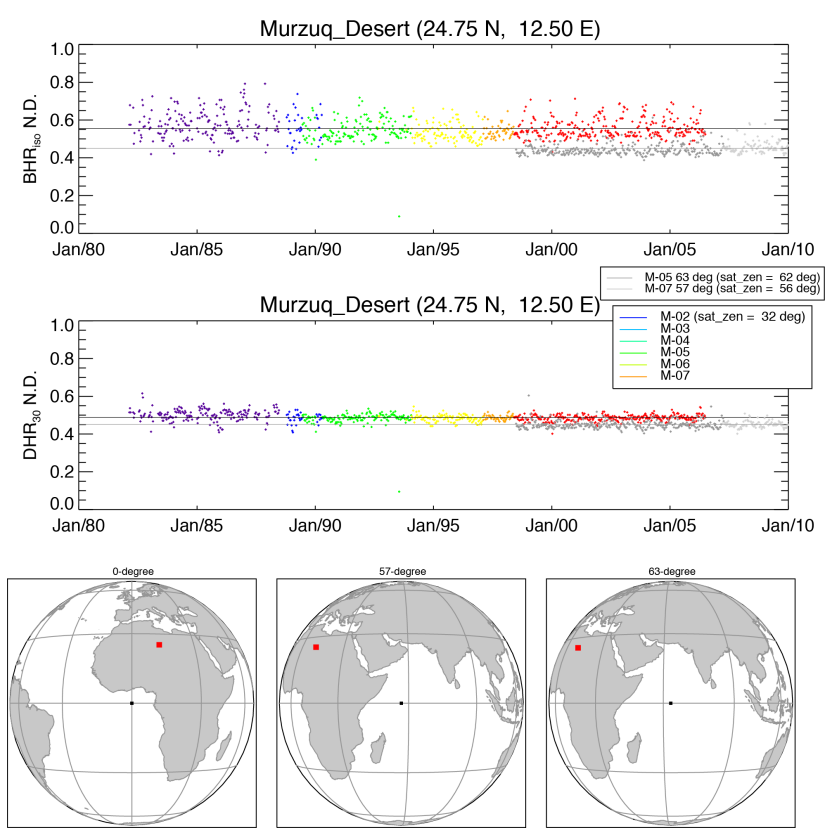

Figure 1. Long-term time series of $\mathrm{BHR}_{\text {iso }}$ (upper panel) and DHR (middle panel) for the Murzuq Desert site. The position of the target site on the respective $0^{\circ}$ and IODC field of view is shown in the bottom panel. The coloured dots refer to $0^{\circ}$ coverage, the grey dots to IODC coverage. The dark and light-grey lines show the long-term averages for the two coverages. The spectral to broadband conversion coefficients from Loew and Govaerts (2010) have been applied.

\section{Temporal consistency}

The confidence level on the temporal stability of a data record is fundamental to assess the existence of temporal trends. One way to assess this aspect is to select a set of stable targets, e.g. desert locations and analyse the white and black sky albedo retrievals over multiple years. If the true change in land surface albedo, represented by the time series slope, is exactly zero, one can expect the retrieved slopes to be distributed around zero and the scatter to be associated with the measurement uncertainty. The time series for four desert targets are shown in Figs. 1-4. The visible channels of the MVIRI instrument onboard the MFG series are slightly different (e.g. Lattanzio et al., 2013) and a spectral conversion is necessary to compare them. The coefficients proposed by Loew and Govaerts (2010) have been applied to convert the spectral albedo into a common broad band $(0.3-3.0 \mu \mathrm{m})$ value. The individual time series of both ODEG and IODC are very homogeneous. Especially the central Saharan sites, Libya and Egypt One, and, to a slightly lesser degree, the Murzuq Desert site, also appear to be extremely stable (see Table 3). A similar stability is observed for further sites in both arid and non-arid areas (Fell et al., 2012). An exception is represented by the Omani Desert site (Fig. 4). In this case a trend towards increasing surface albedo is found, especially for IODC retrievals. The same site also shows a bias
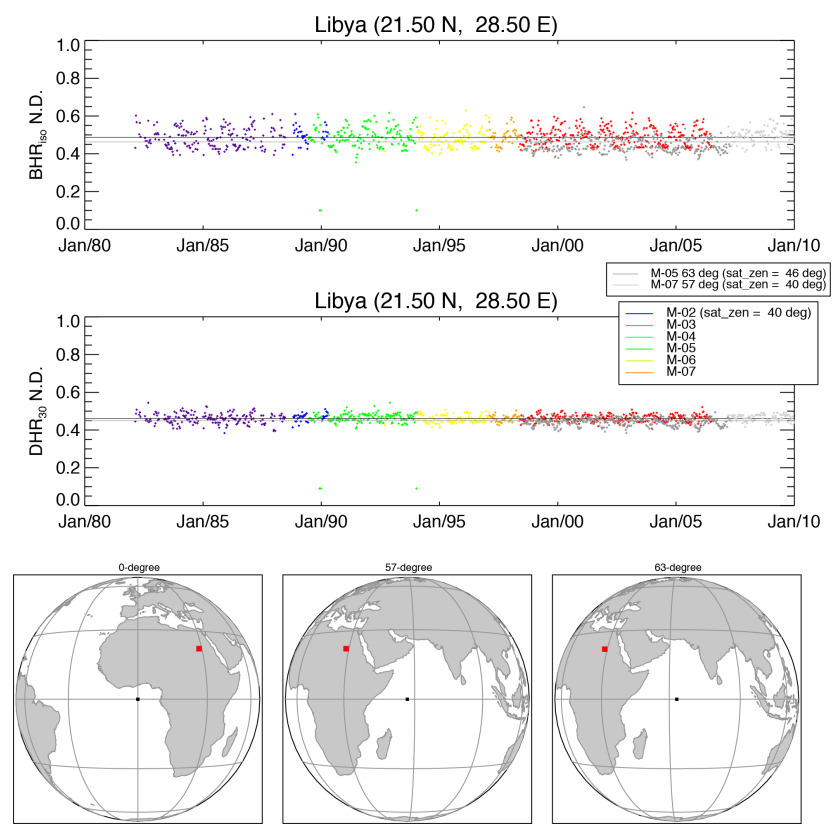

Figure 2. Same as Fig. 1 but for the Libyan Desert site.

between ODEG and IODC. The origin for such a bias can very likely be traced back to the different observation geometry. Those differences may lead to systematic deviation in the DHR retrieval that can reach values of up to 10 and up to $20 \%$ for $\mathrm{BHR}_{\text {iso }}$. The variations in $\mathrm{BHR}_{\text {iso }}$ appear greater than the corresponding retrieval in DHR. The reason behind this difference is not clear. One possible explanation could be the higher sensitivity of the $\mathrm{BHR}_{\text {iso }}$ to aerosol retrieval and quantification. Apart from the specific mentioned cases, the results of the regression analysis shown in Table 3 indicate that the temporal stability of the MSA CDR is generally better than \pm 0.01 per decade, matching the GCOS requirements.

\section{Uncertainty assessment}

The uncertainty assessment focused on the impact of aerosol and undetected clouds. Aerosol retrieval is particularly challenging over bright surfaces because the contributions to the radiometric quantities measured from aerosol and surface albedo show very similar patterns. Undetected clouds lead to a systematic overestimation of surface albedo above both dark and bright surfaces, though the issue is more relevant on tropical forest due to the higher mean cloud coverage. Because the retrieval of surface albedo and AOD is jointly performed, an overestimation (underestimation) of the aerosol contribution leads to an underestimation (overestimation) of the surface contribution. The impact of an incorrect estimation of the aerosol contribution was assessed through the comparison of MSA AOD estimates against measurements taken at AERONET stations. In general there is 
Table 3. Regression slopes for the four sites shown in Figs. $1-4$. Values exceeding \pm 0.01 decade $^{-1}$ are in bold. IODC data are restricted to the $63^{\circ}$ coverage (MVIRI-5) to avoid potential effects caused by the different observation angles of IODC_63 and IODC_57.

\begin{tabular}{|c|c|c|c|c|c|}
\hline Name & Location & $\begin{array}{r}\text { ODEG } \\
\text { BHR }_{\text {iso }}\left[1 \text { decade }^{-1}\right]\end{array}$ & $\begin{array}{r}\text { IODC } \\
\text { BHR }_{\text {iso }}\left[1 \text { decade }^{-1}\right]\end{array}$ & $\begin{array}{r}\text { ODEG } \\
\left.\text { DHR [1 decade }{ }^{-1}\right]\end{array}$ & $\begin{array}{r}\text { IODC } \\
\left.\text { DHR [1 decade }{ }^{-1}\right]\end{array}$ \\
\hline Murzuq Desert & $24.75^{\circ} \mathrm{N}, 12.50^{\circ} \mathrm{E}$ & -0.0084 & 0.0102 & -0.0325 & 0.0099 \\
\hline Libya & $21.50^{\circ} \mathrm{N}, 28.50^{\circ} \mathrm{E}$ & 0.0037 & -0.0011 & 0.0085 & -0.0011 \\
\hline Egypt One & $27.12^{\circ} \mathrm{N}, 26.10^{\circ} \mathrm{E}$ & 0.0083 & -0.0006 & 0.0071 & -0.0006 \\
\hline Omani Desert & $19.00^{\circ} \mathrm{N}, 55.50^{\circ} \mathrm{E}$ & 0.0170 & -0.0437 & 0.0133 & -0.0421 \\
\hline
\end{tabular}
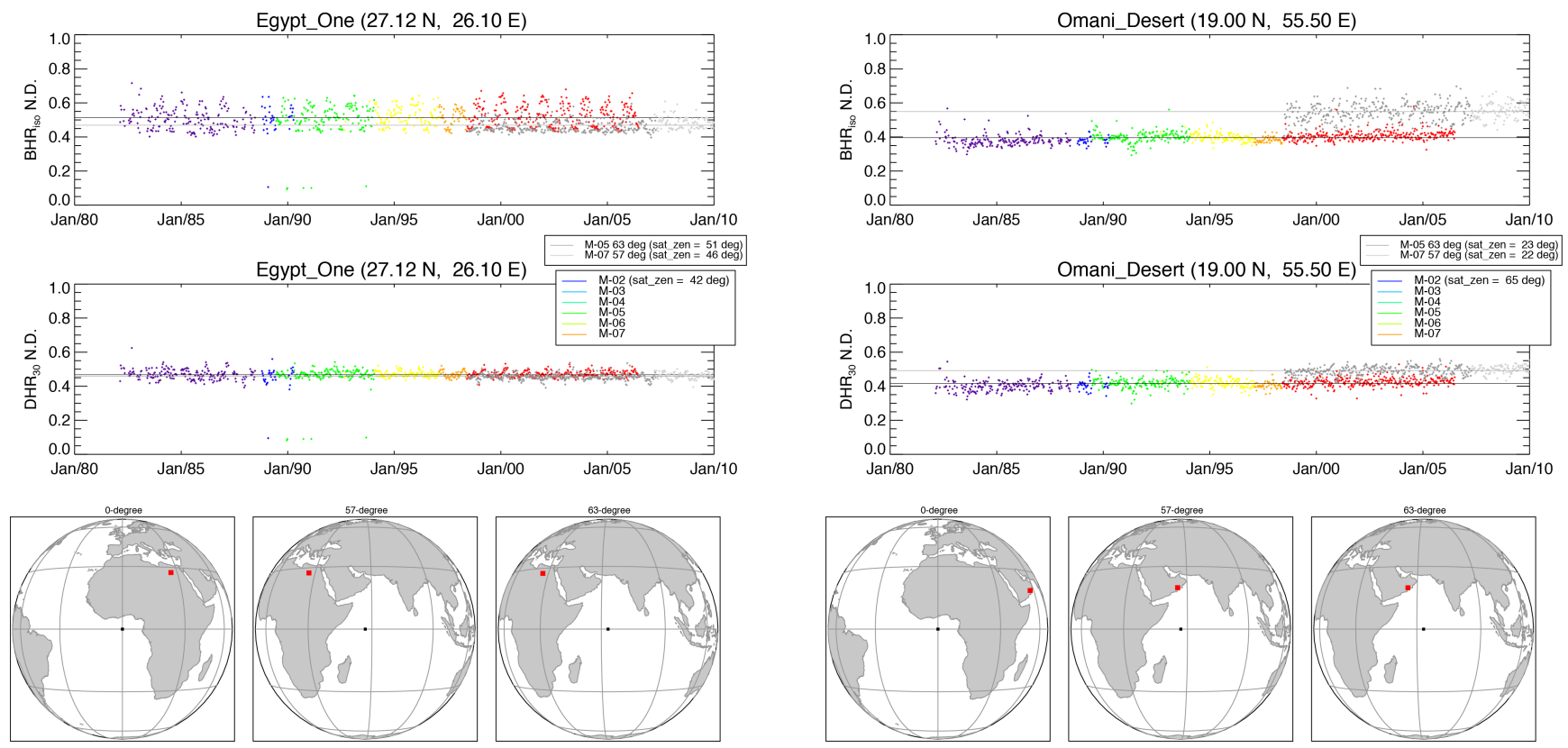

Figure 3. Same as Fig. 1 but for the Egypt One site.

good agreement between MSA and AERONET AOD, even though MSA is based on a simple continental aerosol model. MSA retrieval is bound to discrete AOD values in the range between 0.1 and 1.0. As a result, MSA will tend to overestimate the AOD in cases where the real value is $<0.1$. MSA seems to underestimate AOD for values above 0.5 . It should be pointed out that this statement is based on a limited number of observations. Statistically, the AODs from IODC and ODEG show a very similar performance against AERONET (see Fig. 5).

In the current MSA implementation no external ancillary cloud mask information is applied. In the first retrieval step, a simple procedure is applied to detect clouds and cloud shadows (Pinty et al., 2000b). This procedure analyses the daily variation of top-of-atmosphere bidirectional reflectance factors (ToA BRF) statistically in order to detect values deviating from the expected values in case of clear sky conditions. The impact of undetected clouds emerges from the comparison between the MSA products with satellite and in situ measurements. A comparison between MSA and MSG

Figure 4. Same as Fig. 1 but for the Omani Desert site.
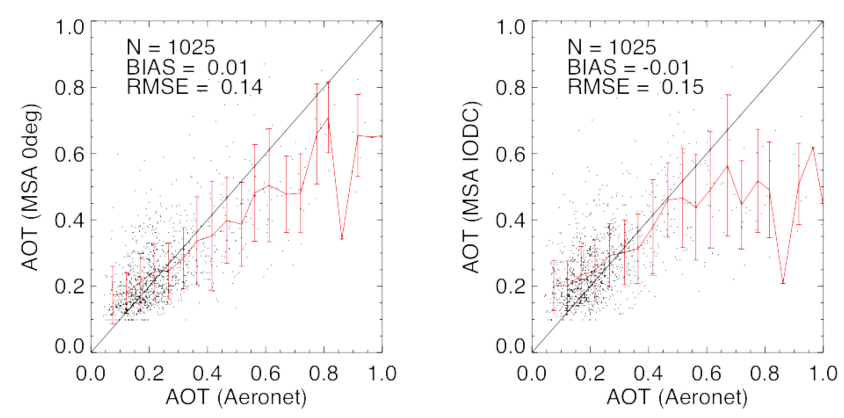

Figure 5. Comparison of AERONET and MSA aerosol optical depth (AOD). Left panel: 0DEG coverage, right panel: IODC_57 and IODC_63.

SAF black sky albedo retrievals for barren and evergreen broadleaf surface types, representative of tropical forest and desert sites is shown in Figs. 6 and 7, respectively. The results clearly reveal that the cloud detection procedure is not adequate for patterns with persistent cloud cover during the 

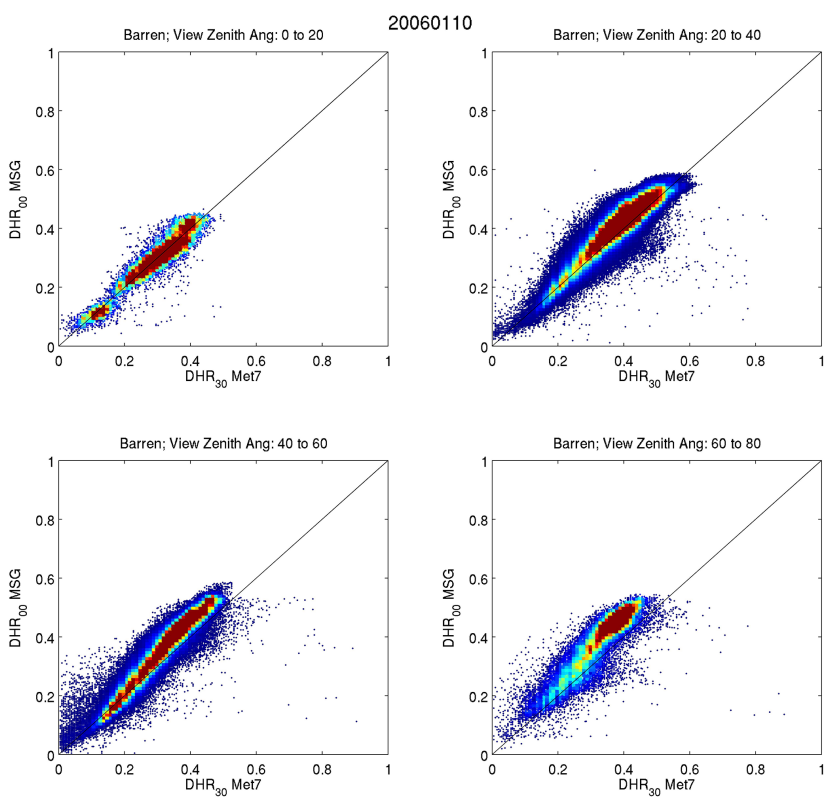

Figure 6. Scatter plots of MSA DHR30 ( $x$ axis) vs. SEVIRI DHR ( $y$ axis) for pixels classified as "barren" for the 1-10 January 2006 period. Pixels are grouped according to MSA viewing angle ranges indicated in the top of each panel.

day such as in the evergreen broadleaf forest areas. This is evident from Fig. 7 where the long tail of high MSA albedo retrievals is not mirrored in the SEVIRI data set. This effect is absent in the case of barren surface type. On the other hand, the comparison over the latter reveals a conditional bias, with deviations from the $1: 1$ line increasingly higher for brighter surfaces. Figure 6 also shows that this effect increases with viewing angle.

The MSA data set has been compared with in situ measurements acquired during the SAFARI campaign (Privette et al., 2005). This comparison does not focus on the quantitative analysis of the difference in the retrieval but aims to highlight the issue related with non-removed cloudy pixels in the case of the MSA CDR. MSA products derived for the ODEG and IODC missions have been analysed for a site located in Mongu (Zambia) for years 2000, 2001, 2002. The BHR (blue sky albedo) is the quantity measured by the in situ instrument. Blue sky albedo values are expected to lie between the corresponding BHR $\mathrm{Bso}_{\text {iso }}$ and DHR values (Pinty et al., 2005). This expected behaviour is confirmed in most of the cases for the ODEG mission (Fig. 8) and for the IODC mission (Fig. 9). The decrease in accuracy and precision of the retrieval in winter, during the rainy season, is expected and is due to undetected clouds in the MSA CDR.

\section{Quality improvement}

One clear outcome of the validation study is that the most relevant issue impacting the quality of the MSA CDR is the
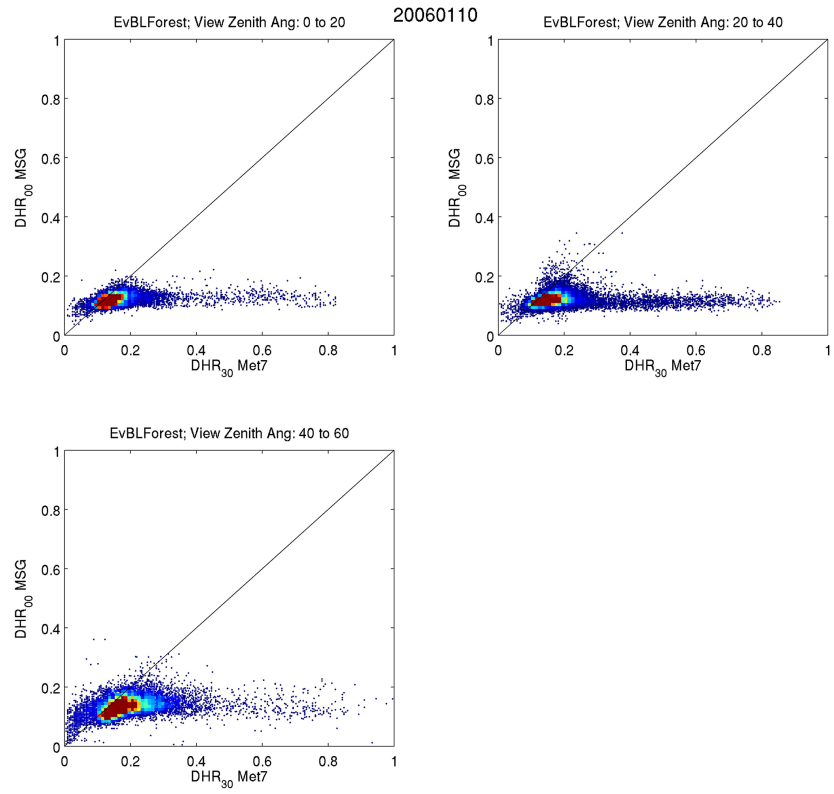

Figure 7. Same as Fig. 6 but for pixels classified as evergreen broadleaf forest. The impact of undetected cloud for the MSA CDR is clearly represented by the tail of high albedo values.
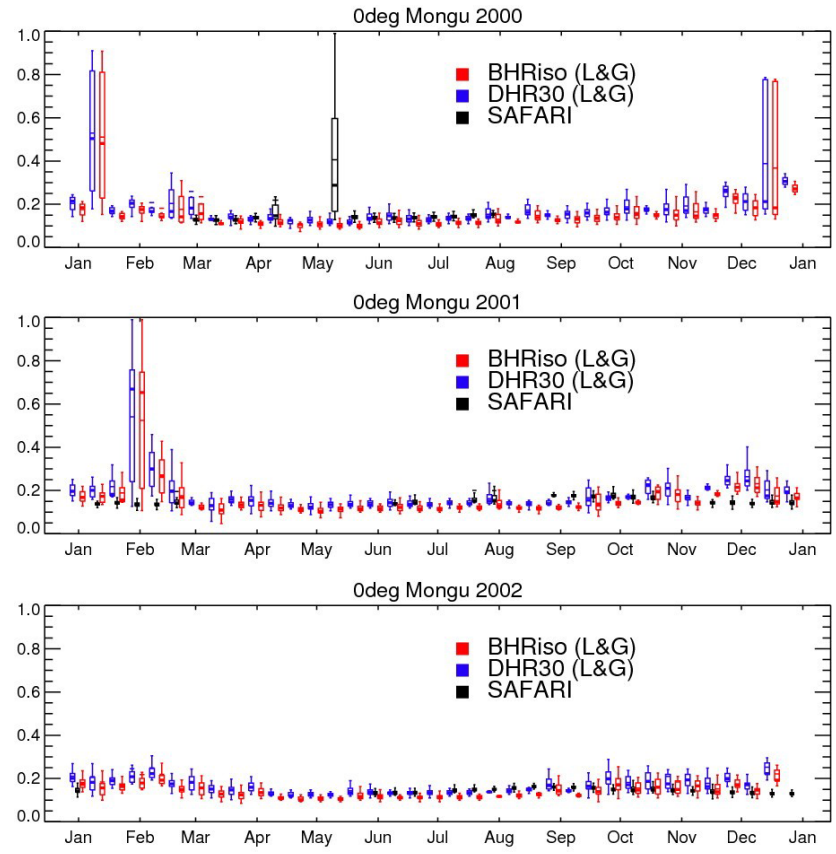

Figure 8. Comparison of MSA vs. in situ albedo observations for the ODEG mission. The box-and-whisker diagrams represent the spatial variability of the MSA retrievals within a $3 \times 3$ window centred at Mongu (Zambia). For the in situ observations (black), the diagrams represent the temporal variability within a 10-day observation period. 

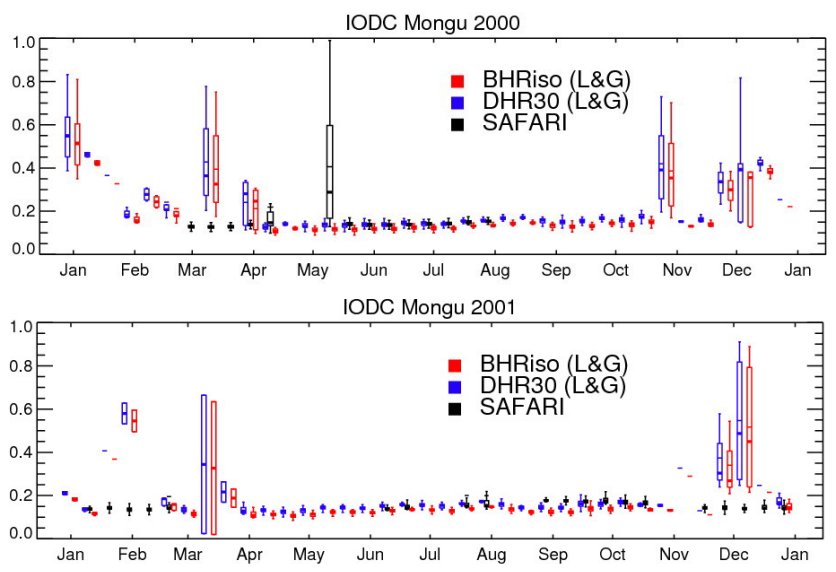

IODC Mongu 2002

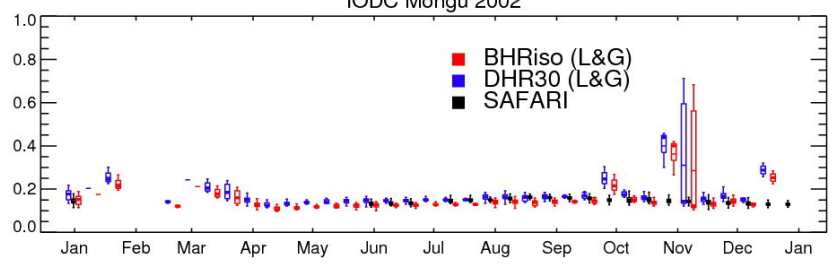

Figure 9. Same as Fig. 8 but for the IODC mission.

partial failure in detecting clouds. A twofold strategy has been designed for tackling the problem. The first part relies on a robust and reliable cloud masking scheme applied during the surface albedo retrieval. The second part of the strategy, referred to as cloud removal and applicable only after the generation of the complete data record, exploits the information in the time domain included in the natural albedo seasonal variation in order to detect and remove outliers.

\subsection{Cloud masking}

Two different cloud masks have been generated and tested. The first one is derived using a simple method, using the MVIRI VIS band only. Analysing all images acquired during a full month, a BRF background map for each image acquisition interval (30 min for MVIRI) is built up. In the second step, all MVIRI images for that month are compared with the previously generated background to detect outliers due to cloud coverage (background cloud mask, BCK CM) using a simple threshold method. The second cloud mask (CMSAF CM) has been generated as a prototype by the Satellite Application Facility on Climate Monitoring, CMSAF (Khlopenkov and Trishchenko, 2007; Fontana, 2010). This procedure uses both the visible and the thermal band at $10.8 \mu \mathrm{m}$. Common to both methods is that they can be, in principle, applied to all past and present GEO satellites (MSG, GOES, GMS, MTSAT). This aspect is particularly relevant if considering the application within the SCOPECM framework.

The comparison of albedo estimates obtained with different cloud screening approaches for a tropical rain forest re- gion (Fig. 10) sensed under a small view zenith angle (VZA) shows that the impact of using a cloud mask has significantly reduced the number of DHR values above 0.4. Since vegetated areas are generally characterized by low albedo, DHR values above 0.4 are unrealistic and most likely due to undetected clouds. It is worth noting that this effect is more evident when using the CMSAF CM (bottom left panel) than the simple BCK CM (bottom middle panel). The added value of the CMSAF CM exploiting both the visible and the infrared channels over the simple BCK CM based on the visible channel is only that it better constrains the DHR values on the range below 0.4 (bottom right panel). It can also be noted how the pattern of the scatter plot is similar to the comparison shown in Fig. 7 between the MSA CDR (with no cloud mask) and the SEVIRI-based albedo data set. As expected, cloud masking has a very marginal effect on desert regions (Fig. 11) where clear sky conditions dominate. The analysis for another tropical rain forest regions sensed under large VZA (Fig. 12) shows that the use of a cloud mask efficiently removes unrealistically high albedo values caused by cloud contamination, leading to a significant decrease of the number of retrieved DHR values as shown in Table 4. Again, the effect is much more pronounced when using the CM SAF $\mathrm{CM}$. This result is not surprising as visible-only cloud masking at high VZA is likely to fail due to decreased contrast at higher atmospheric path lengths. The fewer but more reliable retained DHR observations will likely increase the overall quality of the data record.

\subsection{Cloud removal}

The exploitation of a cloud mask for the generation of highquality surface albedo is fundamental and has shown very positive impact on the retrieval. Unfortunately, due to the limited spectral and spatial information provided by MVIRI, a non-negligible number of cloud-affected observations will not be identified as such. Undetected clouds can be removed in a post-processing approach. One strategy is to exploit the information contained in surface albedo time series covering several years. Under normal conditions, surface properties remain relatively stable over multiple years, respecting a natural seasonal variation. This assumption might not hold if in a certain year an area had suffered from natural or anthropogenic extreme events (wild fires, flood or droughts). Nevertheless such events can be considered statistically not significant and treated as outliers. The proposed strategy relies on the creation of broadband $(0.3-3.0 \mu \mathrm{m})$ seasonal DHR maps to be used as a climatological background and it is performed in three steps. In the first step for each pixel $i$ in the processed region of interest (ROI), the time series, including all available periods $t$ in the time range (TR) 1982 to 2002, is analysed. Due to the fact that the VIS band of the MVIRI instruments onboard the MFG platforms are different (e.g. Lattanzio et al., 2013) a spectral to broadband conversion is necessary for comparing them. The conver- 
Table 4. Impact of a cloud mask applied to the MSA processing on the number of retrieved pixels (total higher than a threshold of 0.4).

\begin{tabular}{lrrr|rrr}
\hline & \multicolumn{3}{c|}{ Retrieved pixels } & \multicolumn{3}{|c}{ Above threshold (0.4) } \\
& NO CM & CMSAF CM & BCK CM & NO CM & CMSAF CM & BCK CM \\
\hline Forest (Africa) & $90 \%$ & $92 \%$ & $91 \%$ & $1 \%$ & $0 \%$ & $0.01 \%$ \\
Desert & $100 \%$ & $100 \%$ & $100 \%$ & $47.9 \%$ & $47.7 \%$ & $47.9 \%$ \\
Forest (South America) & $51 \%$ & $17 \%$ & $36 \%$ & $15 \%$ & $0.03 \%$ & $1.2 \%$ \\
\hline
\end{tabular}
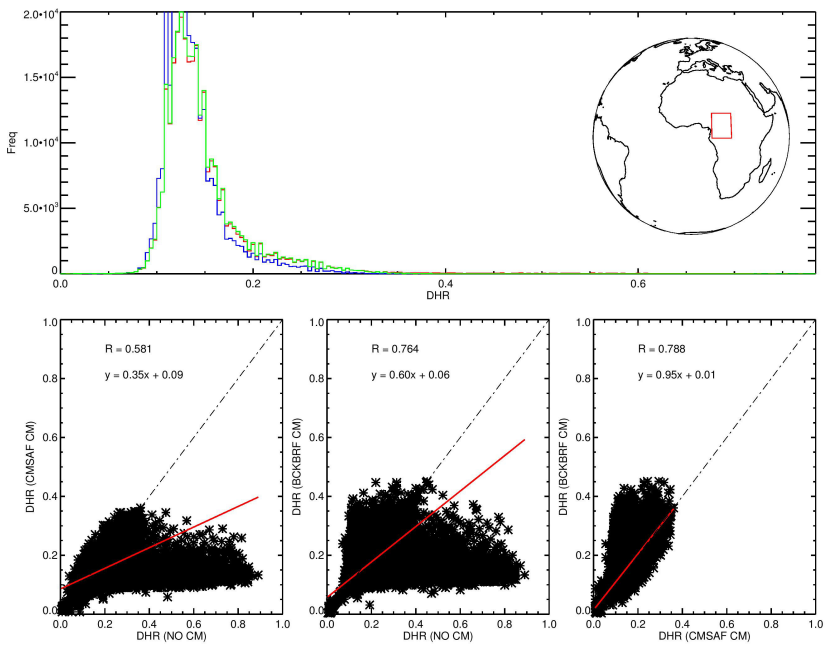

Figure 10. Tropical forest region viewed under a low view zenith angle. Upper panel: distributions of surface albedo retrieved with no cloud mask (NO CM; red), with a single-band (VIS) cloud mask (BCK CM; green), and with the cloud mask developed by the CM SAF (CMSAF CM; blue). Lower panels: scatter plots of albedo estimates using the cloud mask scheme indicated in the respective $x$ and $y$ axis.
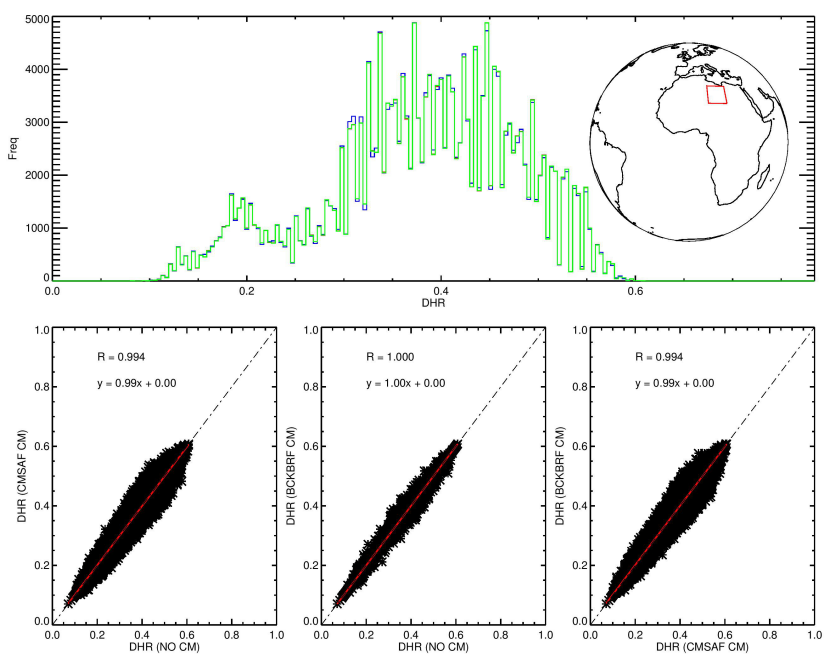

Figure 11. Same as Fig. 10 but for a desert area.
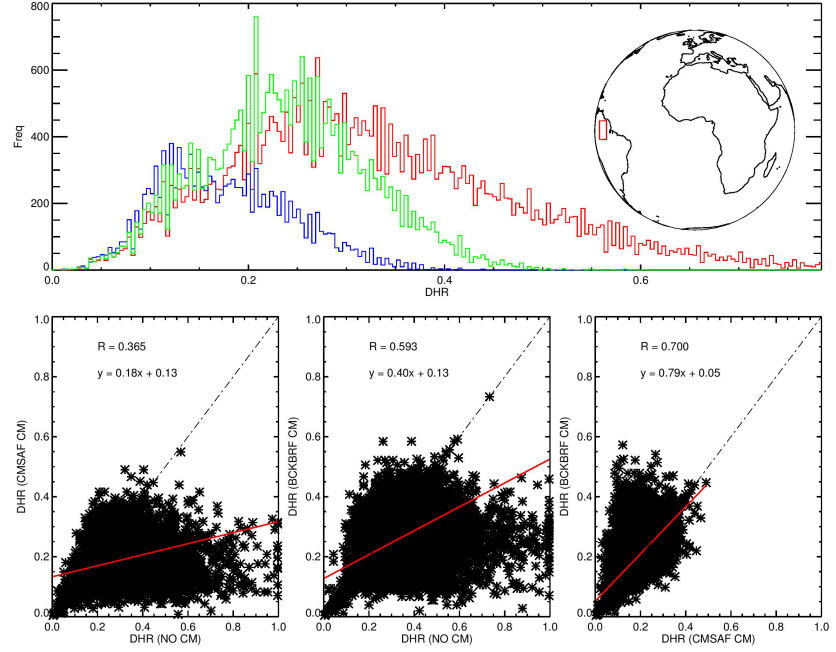

Figure 12. Same as Fig. 10 but for a tropical forest area viewed under high view zenith angle.

sion has been performed using the coefficients proposed by Loew and Govaerts (2010). If the broadband DHR value in the time series for the pixel $i$ in the ROI and period $t$ in TR is noted as $\mathrm{DHR}^{\mathrm{BB}}(i, t)$ and referring to the temporal mean value as $\overline{\operatorname{DHR}^{\mathrm{BB}}(i)}$ and standard deviation as $\sigma^{\mathrm{BB}}(i)$, the ensemble $\mathcal{L}_{n}(i)$ of retrievals, classified as potentially cloudcontaminated and removed as noise for the pixel $i$, satisfies the condition:

$$
\begin{aligned}
\mathcal{L}_{n}(i) & =\left\{\mathrm{DHR}^{\mathrm{BB}}(i, t)>\overline{\mathrm{DHR}^{\mathrm{BB}}(i)}+3 \sigma^{\mathrm{BB}}(i)\right\} ; \\
\forall t & \in \mathrm{TR},
\end{aligned}
$$

assuming a normal distribution and an upper cut-off of $3 \sigma$. This is a standard threshold value for a "near certainty" condition. The standard deviation and the mean value can be affected by outliers if they are a significant population in the data distribution. For this reason, sometimes the median and mean absolute deviation are used as they are not affected by outliers, resulting in a more selective filter. At this stage the usage of mean and standard deviation has been preferred to limit the retrievals treated as outliers. As a result of this step, intermediate "de-noised" MSA DHR products are created for the full ROI of each period $t$ in TR. These products are a copy of the original MSA data set but with all retrievals satisfying Eq. (1) removed. In the second step the 

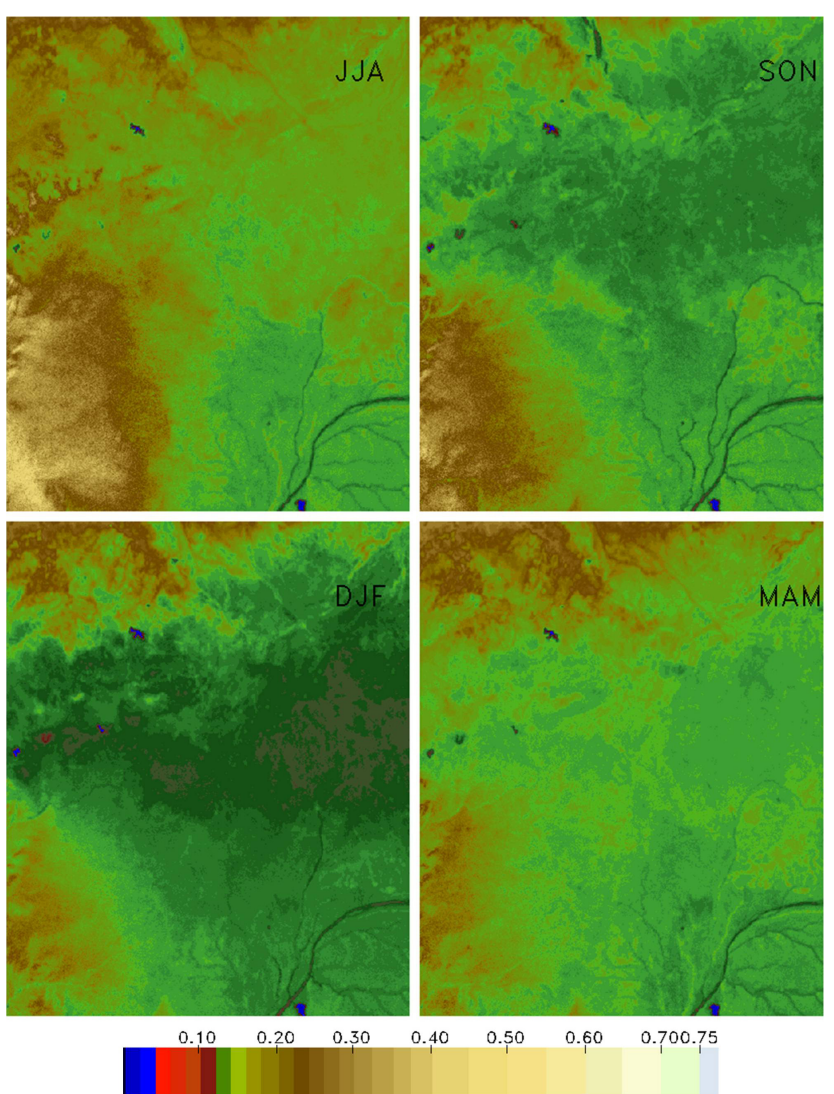

Figure 13. Background albedo maps for the four seasons. DJF (bottom left), MAM (bottom right), JJA (upper left) and SON (upper right).

seasonal DHR background maps are created. The 12 months in the year are grouped into four seasons: DJF (December, January, February), MAM (March, April, May), JJA (June, July, August) and SON (September, October, November). All the "de-noised" retrievals $\operatorname{DHR}_{\mathrm{d}}^{\mathrm{BB}}\left(i, t_{s}\right)$ in each of the four groups are averaged, using the estimated DHR uncertainty $\delta_{\text {DHR }}$ (Govaerts and Lattanzio, 2007) as weight. For each pixel $i$ the background value is

$$
\begin{aligned}
& \operatorname{DHR}_{\mathrm{bck}}^{\mathrm{BB}}(i, s)=\frac{\sum_{t_{s}} \mathrm{DHR}_{\mathrm{d}}^{\mathrm{BB}}\left(i, t_{s}\right)\left(1 / \delta_{\mathrm{DHR}}\left(i, t_{s}\right)\right)}{\sum_{t_{s}} 1 / \delta_{\mathrm{DHR}}\left(i, t_{s}\right)} ; \\
& s=1, \ldots, 4
\end{aligned}
$$

where $s$ is the season index and $t_{s}$ is the index running on all periods $t$ included in season $s$. Retrievals with lower uncertainty will have a higher relevance in the calculation of the average value. An example of such background maps for the same ROI in Africa analysed in Fig. 10 is given in Fig. 13. The third and final step consists of screening the cloudy pixel out from the original MSA products. A simple threshold method has been adopted. For each period $t$, the ensemble $\mathcal{L}_{c}(t)$ of the retrievals, removed because it is

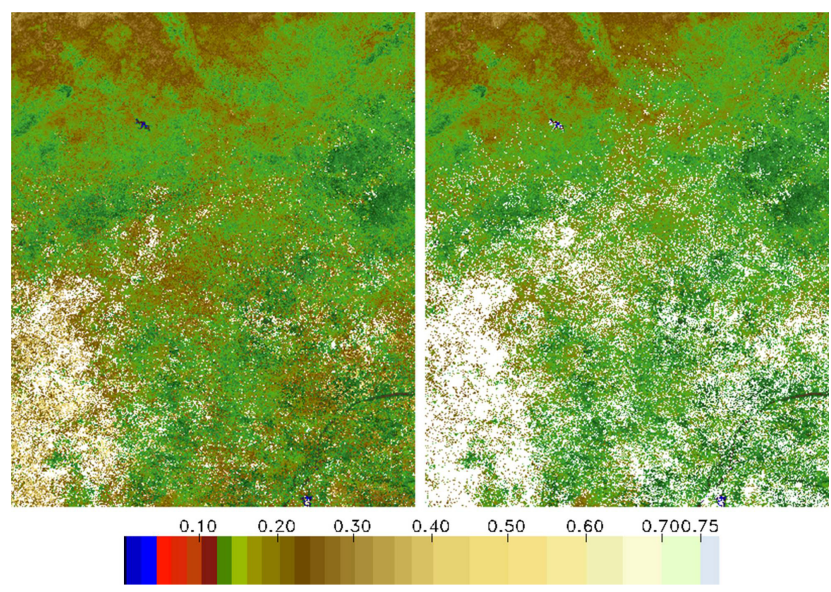

Figure 14. Cloud screening example for Meteosat-7. The period is 1-10 May 2001. The original MSA product is shown on the left panel and the cloud-decontaminated one on the right panel.

potentially cloud-contaminated, satisfies the condition:

$$
\begin{aligned}
\mathcal{L}_{c}(t) & =\left\{\mathrm{DHR}^{\mathrm{BB}}(i, t)>(1+T) \mathrm{DHR}_{\mathrm{bck}}^{\mathrm{BB}}(i, s)\right\} ; \\
\forall i & \in \mathrm{ROI},
\end{aligned}
$$

where $\operatorname{DHR}_{\mathrm{bck}}^{\mathrm{BB}}(i, s)$ is the background value for pixel $i$ and season $s$ (see Eq. 2) and $T$ is the threshold. An example of cloud screening achieved with this method for May 2001 is given in Fig. 14. In this case a value of $T=0.40$ has been used. This value corresponds to an increase of $40 \%$ with respect to the background value. This threshold is very conservative and has been defined according to the albedo change amplitude estimated by Govaerts and Lattanzio (2008). In this study it is shown that a change in albedo in the Sahel region due to a drastic alteration in the precipitation regime did not exceed $30 \%$.

The current MSA CDR release, in particular along the intertropical convergence zone (ITCZ), is heavily affected by undetected clouds and its usage to build a background map cannot be considered fully reliable. The present analysis should be repeated after the generation of a new release with the application of a cloud mask. It could also be necessary to implement different thresholds according to the land cover type. Regions not showing a large dynamical change pattern could benefit from a less conservative threshold value. This precaution might be particularly important for snow-covered regions. High values due to snow coverage could be interpreted as clouds and removed. Even considering all current limitations, the cloud removal method shows good potentialities. The advantage of removing undetected clouds with the disadvantage of losing good retrievals must be carefully taken into account when applying such a strategy. Considering that data sets like the MSA CDR are generated for climate monitoring, it is fundamental to provide the users with the best possible quality retrievals, even it this is to be done at the cost of increasing missing data. The gaps due to miss- 
ing retrievals might be filled using gap-filling methods (e.g. Fang et al., 2007) or by providing the users with temporal and spatial averaged products.

\section{Conclusions}

EUMETSAT generated the MSA CDR within the WMO SCOPE-CM framework. The ALBEDOVAL validation study has been performed to assess the quality of the data record. The outcome can be summarized as follows:

- The MSA Climate Data Record agrees well with corresponding values from satellite-derived and groundbased observing systems under many observation conditions, and it presents a high temporal stability.

- There are some quality issues concerning cloud detection and aerosol-related effects related to the use of a single continental aerosol type limited to a set of predefined load values.

- The strengths underline the already high value of the MSA CDR for climate applications. The weaknesses need to be considered for specific applications and shall be addressed in the context of future reprocessing.

The study has clearly demonstrated that for historical satellites where less calibration information is available, such as MVIRI, the MSA CDR shows a very good temporal stability despite all related caveats (higher sensor noise, lack of documentation). For most of the desert sites analysed, the stability satisfies the GCOS requirement. The study has also highlighted some weaknesses needing to be addressed. In particular the presence of undetected clouds affects the overall quality of the data record. The current embedded method relying on the statistical analysis of the ToA BRF does not perform well in a situation of persistent cloud coverage. In order to address such a drawback, a twofold strategy has been designed. A first step consists of the introduction of a reliable cloud mask to remove most of the clouds prior to the generation of the full MSA CDR. Two different cloud masks have been used to generate MSA products for a particular period. These two data sets and the original data set generated without any external cloud masking have been compared. The effect of the cloud mask is negligible in areas where cloud frequency is low (as it is the case of desert regions). The impact on vegetated areas is different according to the viewing geometry. Areas sensed under low view angles show an increase in the total number of retrievals. In the case of high view angles, the effect of the cloud mask is that it reduces the number of unrealistic high albedo values. In the second step, the temporal and seasonal information included in the data set has been exploited. The applied method shows good potentialities for removing spurious cloud-contaminated pixels, though such an approach should be carefully assessed because it might lead to the removal of good retrievals, but it will provide the users with a more robust and reliable data record.

Acknowledgements. A preliminary version of the CM SAF cloud fractional cover (CFC) data set was provided by MeteoSwiss to EUMETSAT as part of their engagement within the EUMETSAT's Satellite Application Facility on Climate Monitoring (CM SAF) and SCOPE-CM.

Edited by: A. Kokhanovsky

\section{References}

Cescatti, A., Marcolla, B., Vannan, S. K. S., Pan, J. Y., Roman, M. O., Yang, X., Ciais, P., Cook, R. B., Law, B. E., Matteucci, G., Migliavacca, M., Moors, E., Richardson, A. D., Seufert, G., and Schaaf, C. B.: Intercomparison of MODIS albedo retrievals and in situ measurements across the global FLUXNET network, Remote Sens. Environ. 121, 323-334, 2012.

EUMETSAT: Meteosat First Generation User Handbook, available at: http://www.eumetsat.int/website/home/Data/ TechnicalDocuments/index.html?lang=EN (last access: July 2015), 40 pp., 2011

Fang, H., Liang, S., Kim, H.-Y., Townshend, J. R., Schaaf, C. L., Strahler, A. H., and Dickinson, R. E.: Developing a spatially continuous $1 \mathrm{~km}$ surface albedo data set over North America from Terra MODIS products, J. Geophys. Res., 112, D20206, doi:10.1029/2006JD008377, 2007.

Fell, F., Bennartz, R., Cahill, B., Lattanzio, A., Muller, J.-P., Schulz, J., Shane, N., Trigo, I., and Watson, G.: Evaluation of the Meteosat Surface Albedo Climate Data Record (ALBEDOVAL), Final Report, 119 pp., available at: http://www.eumetsat.int/ website/home/Data/ClimateService/index.html (last access: July 2015), 2012.

Fontana, F.: Evaluation of a probabilistic cloud masking algorithm for climate data record processing: Sparc: a new scene identification algorithm for msg seviri, Visiting Scientist Report 14, EUMETSAT Satellite Application Facility on Climate Monitoring, 2010.

Forster, P., Ramaswamy, V., Artaxo, P., Berntsen, T., Betts, R., Fahey, D. W., Haywood, J., Lean , J., Lowe, D. C., Myhre, G., Nganga , J., Prinn, R., Raga, G., Schulz, M., and Van Dorland, R.: Changes in atmospheric constituents and in radiative forcing, in: Climate Change, The Physical Science Basis. Contribution of Working Group I to the Fourth Assessment Report of the Intergovernmental Panel on Climate Change, edited by: Solomon, S. et al., Cambridge Univ. Press, Cambridge, UK, 2007.

Geiger, B., Carrer, D., Franchistéguy L., Roujean, J. L., and Meurey, C.: Land surface Albedo derived on a daily basis from Meteosat second generation observations, IEEE T. Geosci. Remote, 46, 3841-3856, 2008.

GCOS: GCOS-138 Implementation Plan for the Global Observing System for Climate in Support of the UNFCCC, GCOS-138, 180 pp., 2010.

GCOS: GCOS-154 Systematic Observation Requirements for Satellite-based Products for Climate Supplemental details to the 
satellite-based component of the Implementation Plan for the Global Observing System for Climate in Support of the UNFCCC - 2011 Update, WMO, Geneva, Switzerland, 2011.

Govaerts, Y. M. and Lattanzio, A.: Retrieval error estimation of surface albedo derived from geostationary large band satellite observations: application to Meteosat-2 and -7 data. J. Geophys. Res., 112, D05102, doi:10.1029/2006JD007313, 2007.

Govaerts, Y. M. and Lattanzio, A.: Estimation of surface albedo increase during the eighties Sahel drought from Meteosat observations, Global Planet. Change, 64, 139-145, doi:10.1016/j.gloplacha.2008.04.004, 2008.

Govaerts, Y. M., Lattanzio, A., Taberner, M., and Pinty, B.: Generating global surface albedo products from multiple geostationary satellites, Remote Sens. Environ., 112, 2804-2816, 2008.

Hansen, J., Sato, M., and Ruedy, R.: Radiative forcing and climate response. J. Geophys. Res., 102, 6831-6864, 1997.

Henderson-Sellers, A. and Wilson, M. F.: Surface albedo data for climatic modelling, Rev. Geophys. Space Ge., 21, 1743-1778, 1983.

Holben, B. N., Eck, T. F., Slutsker, I., Tanre, D., Buis, J. P., Setzer, A., Vermote, E., Reagan, J. A., Kaufman, Y., Nakajima, T., Lavenu, F., Jankowiak, I., and Smirnov, A.: AERONET-A federated instrument network and data archive for aerosol characterization, Remote Sens. Environ., 66, 1-16, 1998.

Khlopenkov, K. V. and Trishchenko, A. P.: SPARC: new cloud, snow, and cloud shadow detection scheme for historical $1 \mathrm{~km}$ AVHRR data over Canada, J. Atmos. Ocean. Tech., 24, 322-343, 2007.

Lattanzio, A. Govaerts, Y. M., and Pinty, B.: Consistency of surface anisotropy characterization with Meteosat observations, Adv. Space Res., 39, 131-135, doi:10.1016/j.asr.2006.02.049, 2006.

Lattanzio, A., Schulz, J., Matthews, J., Okuyama, A., Theodore, B., Bates, J. J., Knapp, K. R., Kosaka, Y., and Schüller L.: Land surface Albedo from geostationary satellites: a multi-agency collaboration within SCOPE-CM, B. Am. Meteorol. Soc., 94, 205-214, doi:10.1175/BAMS-D-11-00230.1, 2013.

Loew, A.: Terrestrial satellite records for climate studies: how long is long enough? Theor. Appl. Climatol., 115, 427-440, doi:10.1007/s00704-013-0880-6, 2014.

Loew, A. and Govaerts, Y.: Towards multidecadal consistent meteosat surface albedo time series, Remote Sens., 2, 957-967, doi:10.3390/rs2040957, 2010.

Martonchik, J., Diner, D., Pinty, B., Verstraete, M., Myneni, R., Knyazikhin, Y., and Gordon, H.: Determination of land and ocean reflective, radiative, and biophysical properties using multiangle imaging, IEEE T. Geosci. Remote, 36, 1266-1281, 1998.

Ohmura, A., Dutton, E. G., Forgan, B., Fröhlich, C., Gilgen, H., Hegner, H., Heimo, A., König-Langlo, G., McArthur, B., Müller, G., Philipona, R., Pinker, R., Whitlock, C. H., Dehne, K., and Wild, M.: Baseline Surface Radiation Network (BSRN)/WCRP): new precision radiometry for climate research, B. Am. Meteorol. Soc., 79, 2115-2136, 1998.
Ohring, G., Wielicki, B., Spencer, R., Emery, W. J., and Datla, R.: Satellite instrument calibration for measuring global climate change: report of a workshop, B. Am. Meteorol. Soc., 86, 13031313, 2005.

Pielke, R. A. and Avissar, R.: Influence of landscape structure on local and regional climate, Landscape Ecol., 4, 133-155, 1990.

Pinty, B., Roveda, F., Verstraete, M. M., Gobron, N., Govaerts, Y., Martonchik, J. V., Diner, D. J., and Kahn, R. A.: Surface albedo retrieval from Meteosat: Part 1: Theory, J. Geophys. Res., 105, 18099-18112, 2000a.

Pinty, B., Roveda, F., Verstraete, M. M., Gobron, N., Govaerts, Y., Martonchik, J. V., Diner, D. J., and Kahn, R. A.: Surface albedo retrieval from Meteosat: Part 2: Applications, J. Geophys. Res., 105, 18113-18134, 2000b.

Pinty, B., Lattanzio, A., Martonchik, J. V., Verstraete, M. M., Gobron, N., Taberner, M., Widlowski, J.-L., Dickinson, R. E., and Govaerts, Y.: Coupling diffuse sky radiation and surface albedo, J. Atmos. Sci., 62, 2580-2591, 2005.

Privette, J. L., Mukelabai, M., Hanan, N., and Hao, Z.: SAFARI 2000 Surface Albedo and Radiation Fluxes at Mongu and Skukuza, 2000-2002, Data set, Oak Ridge National Laboratory Distributed Active Archive Center, Oak Ridge, Tennessee, USA, doi:10.3334/ORNLDAAC/786, 2005.

Ramanathan, V., Crutzen, P. J., Coakley, J., Dickerson, R., Heymsfield, A., Kiehl, J., Kley, D., Krishnamurti, T. N., Kuettner, J., Lelieveld, J., Mitra, A. P., Prospero, J., Sadourny, R., Valero, F. P. J., and Woodbridge, E. L.: Indian Ocean Experiment (INDOEX), White Paper, C4, Scripps Institution of Oceanography, UCSD, La Jolla, California 92093-0239, USA, 1995.

Schaaf, C. B., Gao, F., Strahler, A. H., Lucht, W., Li, X. W., Tsang, T., Strugnell, N. C., Zhang, X. Y., Jin, Y. F., Muller, J. P., Lewis, P., Barnsley, M., Hobson, P., Disney, M., Roberts, G., Dunderdale, M., Doll, C., d'Entremont, R. P., Hu, B. X., Liang, S. L., Privette, J. L., and Roy, D.: First operational BRDF, albedo nadir reflectance products from MODIS, Remote Sens. Environ., 83, 135-148, 2002.

Schaaf, C. B., Cihlar, J., Belward, A., Dutton, E., and Verstraete, M.: Albedo and Reflectance Anisotropy, ECV-T8: GTOS Assessment of the Status of the Development of Standards for the Terrestrial Essential Climate Variables, edited by: Sessa, R., FAO, Rome, 2009.

Schaepman-Strub, G., Schaepman, M. E., Painter, T. H., Dangel, S., and Martonchik, J. V.: Reflectance quantities in optical remote sensing - definitions and case studies, Remote Sens. Environ., 103, 27-42, doi:10.1016/j.rse.2006.03.002, 2006.

Trigo, I. F., DaCamara, C. C., Viterbo, P., Roujean, J.L., Olesen, F., Barroso, C., Camacho-de Coca, F., Carrer, D., Freitas, S. C., García-Haro, J., Geiger, B., GellensMeulenberghs, F., Ghilain, N., Meliá, J., Pessanha, L., Siljamo, N., and Arboleda, A.: The satellite application facility on land surface analysis, Int. J. Remote Sens., 32, 2725-2744, doi:10.1080/01431161003743199, 2011. 